\title{
PROPOSTA DE IMPLEMENTAÇÃO DE ERP'S E CURVA ABC NOS SETORES DE ESTOQUES E ATENDIMENTO: ESTUDO DE CASO NA PANIFICADORA BODEGA DO PÃO
}

\section{ARTIGO ORIGINAL}

LIMA, Leandro de Souza ${ }^{1}$, BRASIL, Wanderley Costa ${ }^{2}$, ALMEIDA, Victor da Silva ${ }^{3}$, SANTOS JÚNIOR, Aldemir Pereira dos ${ }^{4}$, ROBERTO, José Carlos Alves ${ }^{5}$

LIMA, Leandro de Souza. Et al. Proposta de implementação de ERP's e Curva $A B C$ nos setores de estoques e atendimento: estudo de caso na panificadora Bodega do Pão. Revista Científica Multidisciplinar Núcleo do Conhecimento. Ano. 06, Ed. 11, Vol. 14, pp. 23-43. Novembro de 2021. ISSN: 2448-0959, Link de acesso: $\quad$ https://www.nucleodoconhecimento.com.br/administracao/estoques-eatendimento, DOI: 10.32749/nucleodoconhecimento.com.br/administracao/estoquese-atendimento

\section{RESUMO}

Mediante à competitividade que envolve o mundo corporativo, deve-se compreender que desenvolver processos de excelência que concebam serviços e produtos com altos padrões de qualidade é o método mais eficaz capaz de sobressair às expectativas de seus consumidores. Deste modo, o presente artigo teve como objeto de estudo a empresa panificadora Bodega do Pão. Foi escolhida a partir da análise das áreas funcionais. Identificou-se a área da Logística como a mais crítica. Detémse como problema de pesquisa o preceito de investigar: Como o investimento em

\footnotetext{
${ }^{1}$ Graduando do curso de Administração.

${ }^{2}$ Graduando do curso de Administração.

${ }^{3}$ Coorientador. Mestre em Engenharia de Processos. Pós-Graduando em Neuropsicopedagogia Institucional. Especialista em Gestão Estratégica de RH. Graduado em Administração e Pedagogia.

${ }^{4}$ Coorientador. Mestre em Ciências do Ambiente e Sustentabilidade na Amazônia. Especialista em Gestão dos Recursos Naturais e Meio Ambiente. Especialista em Metodologia do Ensino Superior. Graduado em Turismo e Administração.

${ }^{5}$ Orientador. Mestrado profissional em Engenharia de produção. Especialização em Gestão em Logística empresarial. Graduação em Administração com Ênfase em Marketing.
}

RC: 102229

Disponível em: https://www.nucleodoconhecimento.com.br/administracao/estoques$\underline{\text { e-atendimento }}$ 
sistemas de informação, juntamente com a ferramenta Curva $A B C$, podem desenvolver a acuracidade do mercado de panificação? Como objetivo geral, buscase: Desenvolver a implementação de ERP's e metodologia $A B C$ nos setores de estoques e atendimento da panificadora Bodega do Pão. Para desenvolver-se o estudo em busca de respostas ao questionamento central, recorreu-se a metodologias específicas. A abordagem é qualitativa, pois parte da coleta de dados e entrevistas, transformando o estudo em exploratório, uma vez que conta com bases bibliográficas. Utilizou-se a ferramenta interventiva $5 \mathrm{~W} 2 \mathrm{H}$ para auxiliar no detalhamento das propostas e para melhor implementar as ações estratégicas. Buscou-se, ao gerenciar os estoques, baseando-se na metodologia de curva $A B C$, o desenvolvimento do giro necessário, possibilitando a redução de desperdícios por meio de software ERP, além de estabelecer capacitação no atendimento ao público e conhecimentos básicos de logística atuantes na produção e estoques. Pretende-se direcionar todos os colaboradores para que proporcionem um melhor atendimento aos clientes, com vistas a unificar a comunicação interna, visando o aumento do nível de satisfação dos consumidores, aderindo um ERP Net Promoter Score e questionários de múltipla escolha que classificam o nível do atendimento e fornecem um melhor direcionamento para a contratação de serviços de venda on-line, o que aumentou a procura pelos produtos e reduziu a quantidade de itens em estoque.

Palavras-chave: ABC, Atendimento, ERP, Estoques, Panificadora.

\section{INTRODUÇÃO}

Entende-se que em todas as instituições prestadoras de serviços ou não há uma constante. Nota-se que a qualidade é a peça-chave, o diferencial mediante o aumento da demanda dos bens oferecidos aos consumidores, e toda a complexidade que seguidamente envolve-os. Somente por meio desta que possibilita-se dominar diretamente o mercado. Assimilando tais conceitos, direcionase o presente estudo de caso realizado na Bodega do Pão, atuante no ramo do comércio de panificação, classificada como empresa de pequeno porte. A orientação para o desenvolvimento do estudo se deu por meio dos fatos coletados no 
Diagnóstico Organizacional executado na organização em questão. Estabeleceu-se, por meio do gráfico das áreas funcionais, que a maior falha estava relacionada ao setor logístico. O item assinalado como objetivo específico estabelece que se almeja: Desenvolver a implementação de ERP's e metodologia $A B C$ nos setores de estoques e atendimento da panificadora Bodega do Pão.

Almeida (2016, p. 64) estabelece que: "o projeto de pesquisa parte de um conjunto de questionamentos fundamentais comumente denominados de problemática em que a síntese é constituída por pergunta ou conjunto de perguntas que norteia o desenvolvimento do projeto como um todo [...]". Em conformidade ao preceito da autora, a problemática central do estudo deseja compreender: Como o investimento em sistemas de informação, juntamente com a ferramenta Curva $A B C$, podem desenvolver a acuracidade do mercado de panificação? Administradores de todas as áreas, baseados na determinação e incessante concorrência, na busca por tornarem-se competitivos no mercado no qual atuam diariamente, para que alcancem uma boa performance, devem considerar as atualizações de seus ramos. Compreende-se que são poucas as pesquisas referentes à abordagem dos conceitos de logística, estoque e atendimento.

No interesse de expandir este conceito, demonstrou-se as propostas por meio da metodologia $5 \mathrm{~W} 2 \mathrm{H}$, que visa à coordenação de ações internas e externas relativas à logística e agregadas às estratégias de atendimento. Estabelecem-se como objetivos específicos a busca por: descrever quais tecnologias de ERP integradas à Curva ABC apresentam-se no mercado; validar na empresa a aplicação dessas ferramentas; e quantificar a acuracidade obtida na panificadora Bodega do Pão. Desejava-se que, com estas ações, itens como: prudência, higiene, eliminação de desperdícios e desenvolvimento do zelo pelos públicos interno e externo, tornassemse tópicos verídicos na instituição, afinal, no setor da panificação, estes são imprescindíveis. 


\section{FUNDAMENTAÇÃO TEÓRICA}

Conforme Pereira, Castilho e Borges (2011, p. 10) "[...] usualmente, a pesquisa surge de uma dúvida, que por sua vez leva à formulação de um problema que deverá ser resolvido por meio da utilização de um método científico". Com base no questionamento cientifico, ocorre a necessidade de gerar resoluções, deste modo, recorre-se a conteúdos já desenvolvidos em busca de formar um direcionamento com os passos iniciais e aponta-se mecanismos para o desenvolvimento e estruturação da temática a ser abordada na pesquisa.

\subsection{CONCEITO DE LOGÍSTICA E ESTOQUE}

Tendo como pretensão facilitar os processos relacionados à rede de suprimentos, apresenta-se o setor Logístico. Este busca atender as necessidades do consumidor tendo como base os mais baixos níveis de custos produtivos. Freitas, Fraga e Souza (2016, p. 241) estabelecem que "[...] é objetivo da logística tornar disponíveis produtos e serviços no local onde são necessários, no momento em que são desejados [...]". Segundo Wille e Born (2012), o processo logístico é reconhecido como um conjunto de procedimentos aplicados desde a manipulação interna à entrega de itens conclusos aos consumidores.

O intuito central da Logística é disponibilizar itens e materiais nos corretos períodos e ambientes. Quanto aos estoques, Silva e Rabelo (2017) delimitam que estes são ambientes onde se detêm recursos concretos por determinado período; compõemse a partir de insumos, peças que aguardam a finalização e/ou envio à distribuição. Para Lemes e Lima (2018, p. 69) "por meio dos estoques, a empresa alcança um de seus principais objetivos, que consiste no atendimento às necessidades dos clientes. Daí a importância deste item para a administração de um negócio". 


\subsubsection{SERVIÇOS DE PANIFICAÇÃO}

Compreende-se por serviço toda e qualquer atividade de mercadejo que ocorre com pelo menos dois componentes: o prestador do serviço (provedor) e o consumidor (receptor). A atuação da prestação de serviços desenvolve-se a cada dia. Toma forma e apresenta-se atualmente como uma forte produtora de capital financeiro no Brasil, contemplando a variedade de necessidades da sociedade. Muitos são os serviços que agregam valores ao mercado. O mercado de panificação é atualmente generalizado, visto que somente o produtor e distribuidor de itens alimentícios perecíveis precisam se preocupar com um pequeno período de validade. No entanto, é possível subdividir o setor de panificação em diversos ramos.

Galli et al. (2020) abordam que a panificação pode ser fragmentada em quatro classificações, sendo elas: Estilo boutiques, que são encontradas em ambientes de classe alta, cujos itens são de exclusiva manufatura ou introduzidos de outras localidades; De serviços, encontradas em ambientes com grandes agrupamentos de empresas, lugares onde há forte fluxo de pessoas; De conveniência, apresentam-se em recintos mais residenciais, agregam grandes variedades de itens nos cardápios; e, por fim, Os pontos quentes, de origem europeia, são apontados como pequenas filiais em localidades diferentes ao centro produtivo da sede, de modo que este estilo reduz os gastos com armazenagem e pessoal envolvido na confecção das mercadorias.

Segundo Veras Junior $(2015$, p. 22) "o setor de panificação apesar de ter um mercado muito amplo, é um setor muito concorrido, e por esse motivo é muito comum algumas empresas não conseguirem manter suas atividades durante muito tempo $[\ldots] "$.

\subsubsection{CURVA ABC E SEUS BENEFÍCIOS}

Trata-se de uma metodologia estabelecida pelo italiano Vilfredo Pareto, em torno de 1897, sendo este um estudo relativo à repartição dos bens de sua região. 
Atualmente, a ferramenta indica três classificações, conforme seu nome relata. A classificação $A$ descreve as peças de superior notoriedade, estabelecidas em $20 \%$ em relação ao total de peças avaliadas e denotam em torno de $80 \%$ de impacto monetário. Já a classificação $B$ implica em graus intermediários, logo, em seguida aos itens da classe $A$, estes manifestam cerca de $30 \%$ dos itens, correspondendo a $15 \%$ da média monetária. Por sua vez, a classificação C representa itens de inferior distinção, compostos em torno de $50 \%$ das peças, fomentando, geralmente, apenas $5 \%$ de faturamento.

Silva e Rabelo (2017, p. 244), em seu estudo, ao analisarem o mercado, entenderam que: "[...] na administração de materiais, a curva $A B C$ tem seu uso específico para estudos de estoques de acabado, vendas, prioridade de programação da produção, tomada de preços em suprimentos e dimensionamento de estoque [...]". A ferramenta de Curva atua como categorizadora da importância das peças em estoque, destacando os itens por relevância, de modo que é possível abordar sabiamente o gerenciamento. Assim sendo, a reposição destas ocorre conforme a realidade do faturamento. Santos e Lubiana (2017) categorizam que a curva $A B C$ é uma importante auxiliadora ao gerenciamento de estoques e, dentre os benefícios, registra-se: ordenar as peças por porte monetário ou delimitar a quantidade.

A divisão dos itens por custo de investimento é uma boa opção a gestores que desejam controlar melhor a tomada de decisões na instituição. Silva (2020, p. 26) afirma que "[...] ela pode ser usada não só para os números coletados na empresa, mas também para estabelecer graus de importância para os produtos".

\subsection{CONCEITO DE SOFTWARES (SISTEMAS DE INFORMAÇÃO)}

Em busca de transpassar a concorrência, indústrias e mercados lidam com o conceito de informação como um bem que indica severa relevância em todos os segmentos de atuação. O conceito é amplo e pode englobar diversos sentidos, dentre estes: técnica, cognição ou algo no sentido abstrato. Ao agregar a concepção 
de informação nas corporações, compreende-se que esta é constituída pelos chamados Sistemas de Informação - SI, os quais, na atualidade, englobam todo o conceito digital, fundamentados na computação. De acordo com Falsarella, Jannuzzi e Sugahara (2014, p. 100) "[...] assim, como fator de ordenação de um sistema, pode-se afirmar que a informação constitui-se como um elemento fundamental e indissociável do sistema empresa [...]".

Os autores Santos, Graciano Neto e Araujo (2017) relatam que, conforme as modificações ocorrem no globo, os softwares de SI também se renovam, o que gerou a necessidade de aderir aos novos recursos e retirar os obsoletos. Isso é cabível mediante às redes conjuntas que se agregam nas instituições.

\subsubsection{EMPREGABILIDADE DE SISTEMAS DA INFORMAÇÃO NA LOGÍSTICA}

Compreende-se que o processo logístico é uma das mais ascendentes atividades das sociedades. No meio corporativo, o conceito denota a sucessão de transporte interna e externa de materiais e insumos. Conforme Santos et al. (2017), no desejo de sobressaírem aos concorrentes, os SI auxiliam na ampliação da performance e dos rendimentos nas atividades logísticas, descrevendo a ação ideal colaborativa, bem como focam na distribuição de informações. Os SI têm revolucionado o método de gerenciamento de informações internas, tornando-se primordiais, uma vez que descrevem, com agilidade, os aspectos ligados ao momento de busca e apresentam meios para a visualização destas informações.

Com o desenvolvimento da TGI, os SI se esbarraram na necessidade de modificar o conceito que relatava os maquinários como isolados. Neste momento, passou-se a vê-los como organismos em um todo. Desta forma, compreende-se que estes são "itens" separados e correlativos de um grupo geral aos quais busca-se informar com destreza e seriedade as informações relevantes à determinação de decisões, sempre baseadas em fatos de pertinência geral. 


\subsection{PRINCÍPIOS DE CAPACITAÇÃO E ATENDIMENTO}

Em todos os setores da instituição, havendo ou não contato com o consumidor final, o atendimento deve ser desempenhado com excelência, afinal, este é como a "vitrine" da instituição. É por meio deste que o consumidor firma suas ideias e preceitos sobre a organização. É por meio do atendimento que o cliente compreende se irá ou não voltar a utilizar os serviços ou comprar os produtos oferecidos por esta. Destacam-se, nesse contexto, os colaboradores, pois são eles o cartão de visitas da empresa, de modo que devem possuir as devidas qualificações, bem como devem ser capazes de compreender e atender os desejos dos clientes. Esta é, portanto, atualmente, a melhor forma de demonstrar a estes que são reconhecidos como prioridade na organização. Sá (2016, p. 01) denota que é: "importante salientar que a capacitação deve ser um processo contínuo de aprendizagem, em virtude da mudança das demandas da sociedade [...]".

Ao recorrer-se à alguma organização ou produtora, variando conforme a espécie de instituição, deseja-se obter uma recepção calorosa, encontrar um ambiente onde os anseios sejam sanados. Portanto, os colaboradores, em qualquer categoria de estabelecimento, seja em órgãos públicos, clínicas médicas ou panificadoras, devem possuir as maestrias cabíveis a tornarem resolutas estas necessidades.

\subsubsection{FERRAMENTA DE FEEDBACK}

Conceitua-se feedback como um recurso de intercomunicação entre os stakeholders e a instituição, tendo como foco principal a melhor representação de quais melhorias podem ser descritas internamente, tanto em questões de atendimento, como em termos gerais quanto aos produtos ou serviços prestados. Esta metodologia auxilia na ampliação do rendimento, pois demonstra onde os erros escondem-se. Stecca e Ávila (2015, p. 48) apontam que "[...] a avaliação de desempenho proporciona um feedback aos colaboradores, sendo o resultado muito importante, tanto para a organização quanto para o colaborador". Aplicar o método nos mercados é de suma imprescindibilidade. A inserção deve ser baseada no intuito de firmar a comunicação 
entre os integrantes da relação trabalhista, isto para que a linguagem da instituição seja a mesma falada por todos os colaboradores.

Deste modo, esta ferramenta permite que os empregados se especializem em suas atribuições e compreendam quais medos e incertezas são verídicos em relação à sua performance. Leite, Nascimento e Matteu (2018) descrevem que os modelos de feedback mais utilizados são: o Positivo, que se aplica para a motivação e intenciona fortalecer as atitudes benéficas; o Corretivo, exprime desejo de transformação, no entanto, a cautela deve ser seguida à risca para não obter um efeito contrário e desmotivar o destinatário; o Insignificante, não busca, contudo, um fim e sempre resulta no efeito contrário ao ouvinte, pois é introduzido com confusão; e o Ofensivo, sendo, portanto, o último classificado, uma vez que se atribui por hostilidade e desestimula o recebedor.

\subsection{SERVIÇOS DE FAST FOOD COM ENTREGAS}

O conceito de alimentação por fast food é o mais crescente nos últimos séculos, uma vez que promove a facilidade de solicitar pela internet algo que você deseja e precisa e, além disso, poderá pagar das mais variadas formas. É uma funcionalidade que praticamente todos e em todos os locais do mundo utilizam. Esta simplicidade também é aplicada no método de avaliação, isto é, desde no atendimento até na qualidade do consumido. Esta avaliação, sendo positiva, desenvolve a atração de mais públicos que as instituições tanto necessitam. Conforme Pereira Filho, Campos e Nóbrega (2015, p. 115) "[...] os fatores que influenciam na escolha do restaurante, encontraram a seguinte hierarquia: variedade, qualidade e sabor da comida, ambiente e higiene, velocidade do serviço, preço, e localização [...]".

Seguindo a linha de pensamento dos autores, o serviço, no geral, inclui a qualidade e o tempo de entrega como os mais fortes influenciadores no desejo de aquisição do consumidor. O reconhecido atualmente como cliente 4.0 é o solicitante por aplicativos de fast food. Este possui uma vasta variedade de opções em um único ambiente, portanto, dispõe de altas pretensões bem classificadas, além de optarem 
por aqueles que dispõem produtos com a melhor qualidade e, ainda, atém-se àqueles produtos com menor custo. Se todas as expectativas do consumidor são atendidas com seriedade e este é atendido com excelência, este transmite sua experiência a outros consumidores, que, por sua vez, consideram o feedback no momento de adesão ao serviço.

Para Silva (2020, p. 03) "[...] outros requisitos do consumidor exigente está na eficiência do delivery quanto ao seu imediatismo, a forma que repassa comodidade e a confiança pelo serviço prestado [...]".

\section{MATERIAIS E MÉTODOS}

De acordo como Almeida (2016), compreende-se que o conhecimento é a necessidade de encontrar sapiência, sendo que ela, por sua vez, provém da ânsia de compreender condutas e eventos do cotidiano social. Para que a adesão aos conhecimentos flua da melhor forma, deve-se ter consciência de que os instrumentos e métodos orientam a investigação, tornando-a de mais fácil manejo, decorrendo em uma melhor compreensão.

\subsection{PROCEDIMENTOS METODOLÓGICOS}

Conforme Aragão Neto e Mendes (2017, p. 10) “[...] não existe um único método e sim uma multiplicidade de métodos que procuram atender as necessidades conforme $o$ assunto e a finalidade da pesquisa, bem como as várias atividades das ciências [...]". Desta forma, cabe, ao pesquisador, a tarefa de escolher qual o método melhor adequa-se ao modelo de estudo que este busca efetuar.

\subsubsection{QUANTO À NATUREZA}

Para Shitsuka et al. (2018), a técnica qualitativa descreve significado nas formas que o explorador compreende os ocorridos no decorrer do estudo. Geralmente, essa técnica de pesquisa desenvolve-se por meio de conferências e questionamentos abertos.

RC: 102229

Disponível em: https://www.nucleodoconhecimento.com.br/administracao/estoquese-atendimento 
Souza et al. (2019, p. 29) declaram que "[...] numa pesquisa de cunho qualitativo, a interpretação do pesquisador apresenta uma importância fundamenta [...] enquanto a pesquisa de natureza qualitativa lida com fenômenos [...]".

Mediante ao que os autores proferem, este estudo é de natureza qualitativa. Isto por esta metodologia optar por desenvolver fatos. Neste modelo de pesquisa, as variáveis são pontos-chaves do estudo.

\subsubsection{QUANTO AOS FINS}

Paim, lappe e Rocha (2015, p. 158) reiteram que "[...] o método exploratório realiza descrições precisas da situação e quer descobrir as relações existentes entre seus elementos e componentes [...]".

Os autores Souza et al. (2019, p. 32) afirmam que: "uma das possibilidades de classificar os tipos de uma pesquisa é observar os seus objetivos. Partindo desse critério, há três tipos: descritivas, explicativas e exploratórias."

Neste estudo, utilizou-se do modelo exploratório de pesquisa. Optou-se por este método para melhor desenvolver os resultados e para que, posteriormente, estes venham colaborar com outros pesquisadores.

\subsubsection{QUANTO AOS MEIOS}

Almeida (2016) aborda que a pesquisa pode ser classificada conforme os objetivos e os meios. No entanto, cabe, ao investigador, desenvolver competências que possibilitem o reconhecimento de qual método cientifico mais se adequa ao seu estudo, para, assim, desenvolver soluções ao questionamento base deste.

Segundo Souza et al. (2019), no modelo de pesquisa bibliográfica, o pesquisador pode chegar aos conhecimentos a partir das mais diversas referências, sendo estas desde os volumes impressos até os materiais científicos e conteúdos digitais. 
Portanto, essa metodologia compreende-se como bibliográfica, cuja maior fonte de conteúdo consultado é proveniente de artigos científicos e livros relevantes aos setores administrativo, produtivo e logístico.

\subsection{CARACTERIZAÇÃO DA EMPRESA}

A presente instituição atua pelo nome fantasia de Bodega do Pão e possui o nome registrado por M S DA S MORAES \& CIA LTDA. Encontra-se sediada na Rua Marquesa de Santos, 92, CEP: 69035-520, Coroado, Manaus/AM. A empresa é uma sociedade dos irmãos Moraes, Mauro e Edgar. Oferece a venda de produtos alimentícios no ramo de panificação. Atualmente, a instituição possui uma única unidade e o projeto inicial de desenvolvimento no ramo surgiu em virtude das necessidades financeiras que ambos percorriam no período. Sendo assim, no ano de 1995, no mês de novembro, surgia uma grande produtora de empregos que, por vinte e seis anos, anos busca atender às necessidades da sua localidade.

A instituição de pequeno porte possui instalações subdivididas em dois pavimentos, condizentes com as especificações de segurança estabelecidas pelos órgãos de higiene e segurança. Os maiores desejos da administração geral da empresa dizem respeito ao alcance de novas metas, à produção de melhorias contínuas, bem como almeja-se um melhor desenvolvimento nos processos produtivos.

\section{RESULTADOS E DISCUSSÕES}

O Diagnóstico Organizacional exposto neste estudo foi gerado na empresa que atende pelo nome fantasia Bodega do Pão. O Diagnóstico apresentou as falhas de grande periculosidade ao desenvolvimento saudável da instituição, como demonstra o gráfico 01. Mediante à estas descobertas, na sequência, ressaltam-se os processos que, aplicados em conjunto e desenvolvidos com sisudez, converteramse em benefícios a toda instituição. No gráfico 01 a seguir, revelam-se os resultados da medição do desempenho de cada setor da empresa, sendo que cada área 
demonstrou pontos específicos que estavam em baixo ou alto nível antes da aplicação do estudo.

Gráfico 01 - Média - Desempenho por Área Funcional

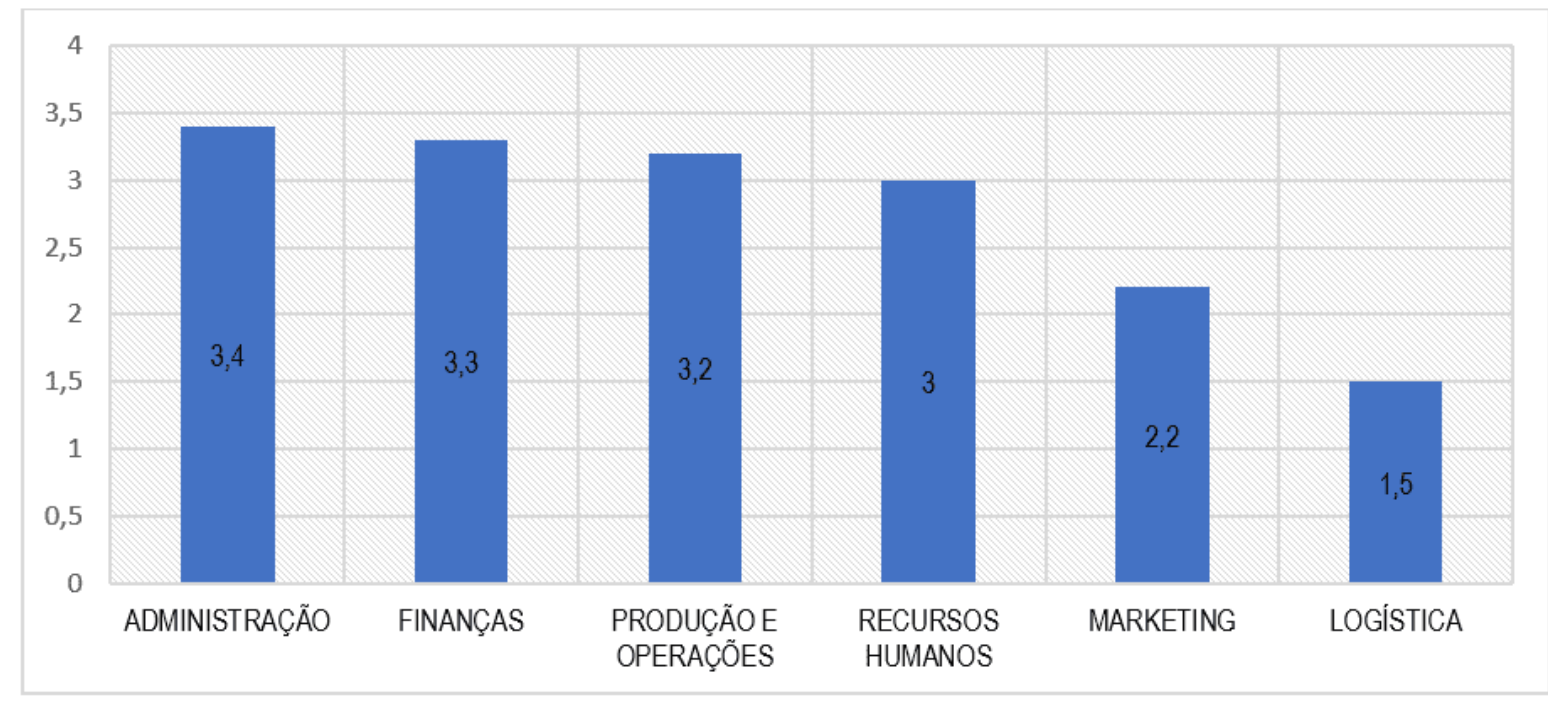

Fonte: Autores, 2021.

Evidenciou-se que na classificação de desempenho funcional na empresa Bodega do Pão, o setor administrativo $(3,4)$ possuía a maior classificação, acompanhado pelas finanças $(3,3)$, produção e operações $(3,2)$, recursos humanos $(3,0)$, marketing $(2,2)$ e, por último, apresentou-se a logística $(1,5)$. Acrescenta-se que 0 departamento logístico carecia de reestruturações. Destacam-se no quadro 01 os tópicos de classificação crítica, cujos aspectos classificaram-se entre pontos muito fortes a muito fracos. Detalha-se, assim, quais subdivisões receberam maior detalhamento e modificação após a aplicação do estudo.

Quadro 01: Logística

\begin{tabular}{|l|l|l|l|l|l|l|}
\hline ÁREA FUNCIONAL & \multicolumn{4}{|l|}{ NÍVEL OU GRAU DE AVALIAÇÃO } \\
\hline LOGísTICA & Ponto & Ponto & Ponto & Ponto & Ponto \\
& muito & forte & médio & fraco & muito \\
& forte & 4 & 3 & 2 & fraco \\
\hline
\end{tabular}

RC: 102229

Disponível em: https://www.nucleodoconhecimento.com.br/administracao/estoquese-atendimento 


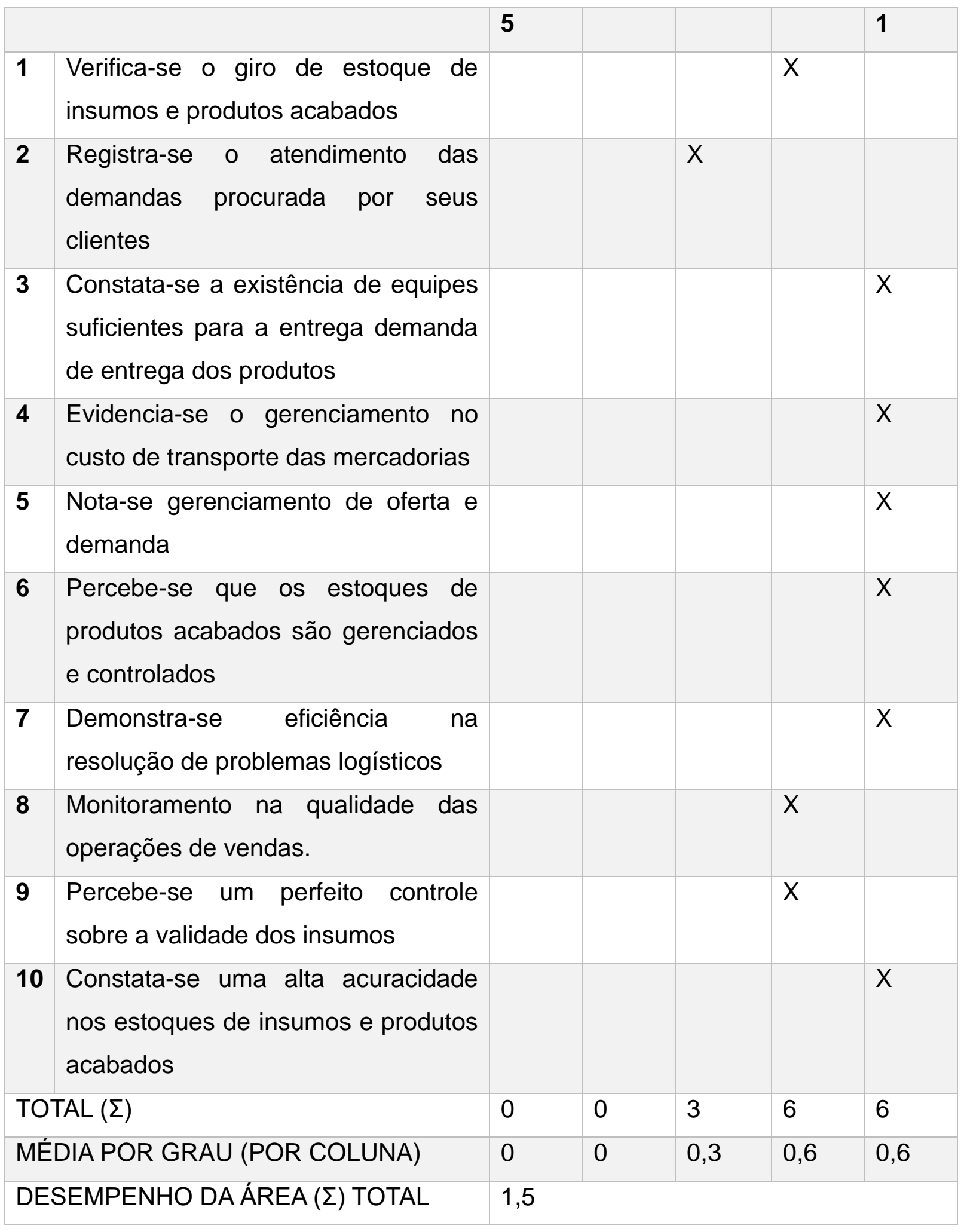

Fonte: Autores, 2021 
Os dados evidenciados no quadro 01 refletem os locais onde se encontravam as problemáticas mais urgentes na área de logística da empresa objeto deste estudo. $O$ quadro ressalta que, nesta repartição, o maior número de dados apontados eram muito fracos. Averiguou-se que o gerenciamento das entregas dos produtos e dos estoques eram os tópicos mais comprometidos da subdivisão. Constatou-se que a instituição necessitava, com urgência e rigor, de ações que solucionem as problemáticas destacadas. Priorizou-se o campo da logística para ajustes. Deste modo, detém-se o seguinte problema de pesquisa: Como o investimento em sistemas de informação, juntamente com a ferramenta Curva $A B C$, podem desenvolver a acuracidade do mercado de panificação?

\subsection{PLANEJAMENTO DE AÇÕES}

Até esta etapa do estudo, coletaram-se dados necessários ao embasamento das ações que foram propostas e seguidas, contudo, como já declarado, a instituição necessitava de adaptações relacionadas ao transporte e estocagem dos itens gerados internamente. Deste modo, as atividades aqui sugeridas maximizaram a acuracidade nos processos logísticos da empresa e, também, reiterou-se a relevância da atenção aos ajustes nos controles de produção e estoque.

Quadro 02 - Ações interventivas

\begin{tabular}{|l|l|l|l|l|}
\hline 01 & Ações Interventivas & Cronologia & Duração & Custo \\
\hline $\begin{array}{l}\text { Implementar software de } \\
\text { sistemas de informação para } \\
\text { gerenciar os estoques } \\
\text { baseando-se na metodologia }\end{array}$ & Ag dias & $\mathrm{R} \$ \mathbf{4 . 0 0 0 , 0 0}$ \\
de curva ABC para \\
$\begin{array}{l}\text { desenvolver o giro necessário } \\
\text { e reduzir desperdícios }\end{array}$
\end{tabular}




\begin{tabular}{|c|c|c|c|c|}
\hline & $\begin{array}{l}\text { todos os colaboradores e } \\
\text { conhecimentos básicos de } \\
\text { logística para os } \\
\text { colaboradores atuantes na } \\
\text { produção e estoques }\end{array}$ & & & \\
\hline 04 & $\begin{array}{l}\text { Implementar ferramenta de } \\
\text { Feedback para verificação da } \\
\text { qualidade dos itens e do } \\
\text { atendimento recebido na } \\
\text { instituição }\end{array}$ & Setembro/21 & 3 Dias & $R \$ 3.000,00$ \\
\hline 02 & $\begin{array}{l}\text { Gerar contratação de serviços } \\
\text { de venda on-line como lfood e } \\
\text { Uber Eats para adicionar } \\
\text { públicos } \\
\text { entregadores }\end{array}$ & Outubro/21 & Permanente & $\begin{array}{l}\text { Conforme o } \\
\text { custo dos itens } \\
\text { e a taxa por } \\
\text { entrega }\end{array}$ \\
\hline & TOTAL & & & $R \$ 8.200,00$ \\
\hline
\end{tabular}

Fonte: Autores, 2021

Conforme o estabelecido no quadro 02, foi possível compreender quais propostas eram viáveis e como sua aplicação no setor logístico da panificadora Bodega do Pão transcreveu-se em reformulações positivas, destacando, de modo enumerado quais avanços foram notáveis com a aplicação destas ações.

\subsubsection{FERRAMENTA DA QUALIDADE PARA IMPLEMENTAÇÃO $5 \mathrm{~W} 2 \mathrm{H}$}

Desenvolvido para o gerenciamento da qualidade, este método exprime sua fundamentação no desenvolvimento de propostas de atividades. Esta ferramenta é acompanhada pelo diagnóstico organizacional que, por sua vez, objetiva padronizar os processos diários nas instituições. 
Conforme Martins (2021, p. 76), a finalidade desta ferramenta é "[...] orientar as ações a serem realizadas visando melhorias, e balanceamento da linha além de gerar indicadores na realização das etapas [...]".

$\mathrm{Na}$ empresa foco deste estudo, esperava-se que, com este método, ocorresse o melhor detalhamento de quais processos do setor que precisavam de melhores cuidados por conta do gerenciamento.

\subsubsection{IMPLEMENTAR SOFTWARE DE SISTEMAS DE INFORMAÇÃO PARA GERENCIAR OS ESTOQUES BASEANDO-SE NA METODOLOGIA DE CURVA ABC PARA DESENVOLVER O GIRO NECESSÁRIO E REDUZIR DESPERDÍCIOS (5W2H)}

Averiguou-se, conforme as informações destacadas na instituição, a necessidade da implementação de uma metodologia correlata entre o gerenciamento da melhor disposição dos itens em estoque e a redução de substratos produtivos.

Analisou-se diversas ferramentas, no entanto, conforme as necessidades e as capacidades disponíveis internamente, constatou-se que, por conta do ramo ser alimentício, o índice de desperdícios por conta de prazo de validade e desinteresse dos consumidores em alguns dos produtos oferecidos e demais fatores afetaram o desempenho da empresa. Optou-se por agregar software de Sistema de Informação Integrado - ERP, conforme se observa no quadro 03, na sequência.

Quadro 03 - Implementar software de sistemas de informação para gerenciar os estoques baseando-se na metodologia de curva abc para desenvolver o giro necessário e reduzir desperdícios

Implementar software de sistemas de informação para gerenciar os estoques baseando-se na metodologia de curva $A B C$ para desenvolver 0 giro necessário e reduzir desperdícios

What O quê? Implementar software ERP formulado conforme a curva ABC 


\begin{tabular}{|l|l|l|}
\hline Why & Por quê? & $\begin{array}{l}\text { Para desenvolver o giro de estoque no intuito de eliminar } \\
\text { desperdícios }\end{array}$ \\
\hline Where & Onde? & Nos estoques da panificadora \\
\hline When & Quando? & Primeira semana de agosto de 2021. \\
\hline Who & Quem? & Área logística, juntamente com administração de compras \\
\hline How & Como? & $\begin{array}{l}\text { Contratação externa de empresa desenvolvedora de sistemas } \\
\text { para verificar se há algum já em mercado o qual enquadrem-se } \\
\text { melhor as necessidades da empresa, caso não haja, solicitar o } \\
\text { desenvolvimento específico para a corporação. }\end{array}$ \\
\hline
\end{tabular}

How Quanto? R $\$ 4.000,00$

Much

Fonte: Autores, 2021

Conforme com o estabelecido no quadro 03, apresentou-se o desenvolvimento da proposta de implementação de um ERP para melhor gerenciamento dos armazéns da panificadora. O plano foi concretizado, conforme proposto aos responsáveis, na primeira semana de agosto de 2021, cujos gestores da área logística, associados ao de compras, ficaram responsáveis pela efetivação das ações. Com esta introdução guiada pela metodologia de Curva $A B C$, houve uma significativa melhora na ordenação dos itens em estoque e, por consequência, constatou-se uma melhora, também, na eficiência no controle dos produtos com seus períodos de conservação e validade dos itens oferecidos aos clientes.

\subsubsection{ESTABELECER CAPACITAÇÃO DE ATENDIMENTO AO PÚBLICO A TODOS OS COLABORADORES E CONHECIMENTOS BÁSICOS DE LOGÍSTICA PARA OS COLABORADORES ATUANTES NA PRODUÇÃO E ESTOQUES (5W2H)}

O atendimento ao público é uma constante entre todos os ramos de comércio, sendo, portanto, decisivo ao sucesso ou fracasso de um negócio. Seja o mercado 
produtivo ou de prestação de serviços, o atendimento atua como demonstrador de como as atividades são desenvolvidas na instituição, primordialmente, reflete em como os colaboradores sentem em relação a como são tratados. As ações dos atendentes repercutem no valor a ser agregado aos produtos da empresa, cuja destreza desenvolve desejo de posterior retorno. No ramo de panificação, compreender a logística envolvida desde a produção ao produto finalizado em armazenagem converte-se em vantagem competitiva.

Quadro 04 - Estabelecer capacitação de atendimento ao público a todos os colaboradores e conhecimentos básicos de logística para os colaboradores atuantes na produção e estoques

\section{Estabelecer capacitação de atendimento ao público a todos os colaboradores e conhecimentos básicos de logística para os colaboradores atuantes na produção e estoques}

\begin{tabular}{|c|c|c|}
\hline What & O quê? & $\begin{array}{l}\text { Capacitar com técnicas de atendimento ao cliente e conceitos } \\
\text { logísticos básicos }\end{array}$ \\
\hline Why & Por quê? & $\begin{array}{l}\text { Para proporcionar um melhor atendimento aos clientes e } \\
\text { estabelecer unificação da linguagem interna }\end{array}$ \\
\hline Where & Onde? & Nos setores de atendimento e logística \\
\hline When & Quando? & Terceira semana de agosto de 2021. \\
\hline Who & Quem? & Departamento gerencial e logístico \\
\hline How & Como? & $\begin{array}{l}\text { O gestor geral, incorpora provisoriamente contratação de um } \\
\text { profissional especializado em aplicar treinamentos aos } \\
\text { responsáveis dos setores. Após o conhecimento ser } \\
\text { implementado na gerência, a gerência por sua vez, deve } \\
\text { repassar aos demais colaboradores todos os conhecimentos } \\
\text { adquiridos. }\end{array}$ \\
\hline
\end{tabular}

How Quanto? $\mathrm{R} \$ 1.200,00$

Much

Fonte: Autores, 2021

RC: 102229

Disponível em: https://www.nucleodoconhecimento.com.br/administracao/estoquese-atendimento 
Em decorrência do exposto no quadro 04, explanou-se a inserção de técnicas de treinamento específicas aos colaboradores da instituição. Esta ação foi aplicada em toda a instituição, contudo, em destaque nos setores de atendimento ao cliente e logística. A implementação ocorreu na terceira semana de agosto de 2021 e os responsáveis foram os gestores gerais e os responsáveis de logística. Com a conclusão desta ação, todos os colaboradores desenvolveram técnicas de capitação e fidelização de clientes, o que aumentou a produtividade e o valor agregado aos produtos.

\subsubsection{IMPLEMENTAR FERRAMENTA DE FEEDBACK PARA VERIFICAÇÃO DA QUALIDADE DOS ITENS E DO ATENDIMENTO RECEBIDO NA INSTITUIÇÃO (5W2H)}

O feedback é uma realidade no mundo corporativo que não pode ser ignorada em circunstância alguma, pois sabe-se que, hoje, é por meio deste que se torna possível a compreensão de qual o nível de satisfação, quais erros cometidos e quais melhorias os clientes viabilizam possíveis à empresa. Deste modo, demonstra-se, no quadro 05 , como a inserção de tal conceito tornou-se benéfica à panificadora Bodega do Pão.

Quadro 05 - Implementar ferramenta de feedback para verificação da qualidade dos itens e do atendimento recebido na instituição

Implementar ferramenta de Feedback para verificação da qualidade dos itens e do atendimento recebido na instituição

\begin{tabular}{|l|l|l|}
\hline What & O quê? & Implementar conceito e ferramenta de Feedback na empresa \\
\hline Why & Por quê? & Para compreensão do nível de satisfação dos consumidores \\
\hline Where & Onde? & Nas instalações que tratam diretamente com os clientes finais \\
\hline When & Quando? & Primeira semana de setembro de 2021. \\
\hline Who & Quem? & $\begin{array}{l}\text { Gestor proprietário em consenso com os setores administrativo } \\
\text { e de compras }\end{array}$ \\
\hline
\end{tabular}




\begin{tabular}{|l|l|l|}
\hline How & Como? & $\begin{array}{l}\text { Efetuando a contratação de desenvolvedora de softwares, para } \\
\text { adesão de um ERP Net Promoter Score e questionários de } \\
\text { múltipla escolha que classifique o nível do atendimento e } \\
\text { possibilite a "caixinha de ideias". }\end{array}$ \\
\hline $\begin{array}{l}\text { How } \\
\text { Much }\end{array}$ & Quanto? & $\mathrm{R} \$ 3.000,00$ \\
\hline
\end{tabular}

Fonte: Autores, 2021.

O proposto no quadro 05 explanou a introdução de conceitos de Feedback que auxiliaram no melhor desenvolvimento da empresa, de modo que este investimento garantiu, no momento de aplicação e mensuração dos resultados direcionados ao desempenho, a possibilidade de desenvolver uma avaliação geral acerca dos processos. Esta ferramenta foi gerida na primeira semana de setembro de 2021, sendo o proprietário da instituição o maior responsável por sua adesão. A ferramenta viabilizou a compreensão acerca de quais desejos eram predominantes aos consumidores quanto aos produtos e atendimento que esperavam receber, bem como apontou-se quais falhas eram mais recorrentes.

\subsubsection{GERAR CONTRATAÇÃO DE SERVIÇOS DE VENDA ON-LINE COMO IFOOD E UBER EATS PARA ADICIONAR PÚBLICOS E NOVOS ENTREGADORES (5W2H)}

Para viabilizar o atendimento a novos públicos e aumentar a produtividade, instituições que atuam terceirizando atividades são grandes alternativas às empresas em crescimento. Sendo assim, por conta da corporação envolver panificação e muitos produtos perecíveis que não podem ser reservados por um longo período de tempo, considera-se que ferramentas de entregas de alimentos foram de extrema eficiência à panificadora Bodega do Pão. Portanto, esta operação demonstra-se a seguir, no quadro 06. 
Quadro 06 - Gerar contratação de serviços de venda on-line como ifood e uber eats para adicionar públicos e novos entregadores

\section{Gerar contratação de serviços de venda on-line como Ifood e Uber Eats para adicionar públicos e novos entregadores}

\begin{tabular}{|l|l|l|}
\hline What & O quê? & Aderir provedores terceirizados de vendas on-line \\
\hline Why & Por quê? & $\begin{array}{l}\text { Para aumentar a procura pelos produtos e reduzir a } \\
\text { quantidade de itens em estoque }\end{array}$ \\
\hline Where & Onde? & Em toda a empresa \\
\hline When & Quando? & Primeira semana de outubro de 2021. \\
\hline Who & Quem? & Departamento administrativo da empresa \\
\hline How & Como? & $\begin{array}{l}\text { Com a contratação dos serviços dos maiores aplicativos de } \\
\text { vendas alimentícias da região }\end{array}$ \\
\hline How & Quanto? & $\begin{array}{l}\text { Conforme o custo de mensalidade e taxas estabelecidas pelos } \\
\text { aplicativos no momento da contratação dos serviços }\end{array}$ \\
\hline
\end{tabular}

Fonte: Autores, 2021

Conforme o apresentado no quadro 06, esta proposta aumentou a procura pelos produtos da empresa e expandiu-se as possibilidades de mercado para a instituição. Esta inserção foi coordenada pelos gestores da instituição. Houve, com esta aplicação, o crescimento da acuracidade logística e melhoras no desenvolvimento dos demais setores.

\section{CONSIDERAÇÕES FINAIS}

Ao associar-se os conceitos logísticos a empresas prestadoras de serviços de panificação, compreendeu-se que seu grande diferencial competitivo encontrava-se na qualidade, mas não somente dos itens ofertados, como também no atendimento desenvolvido por seus colaboradores. Assim, é primordial contemplar o alavanque sobre a concorrência. Deste modo, apresentou-se o presente estudo embasado no Diagnóstico Organizacional. A partir dele, evidenciou-se que a instituição 
necessitava, com rigor e urgência, de ações rápidas, sendo que elas solucionaram as problemáticas destacadas, a priori focalizadas no campo logístico, pois era o que mais necessitava de ajustes. O objetivo geral foi: desenvolver a implementação de ERP's e metodologia $A B C$ nos setores de estoques e atendimento da panificadora Bodega do Pão. Este objetivo deu-se por concluso a partir da ação que buscou solicitar de empresas especializadas no ramo de softwares orçamentos para o desenvolvimento e adesão da ferramenta de ERP's, embasada nos preceitos da metodologia da Curva ABC.

Por sua vez, a problemática da investigação consistiu em constatar: como o investimento em sistemas de informação, juntamente com a ferramenta Curva $A B C$, podem desenvolver a acuracidade do mercado de panificação? Esta questão tornouse resoluta a partir da ação interventiva de adesão do software ERP, tendo sido este incorporado na instituição. Este, por ter bases na Curva $A B C$, proporcionou o melhor controle dos estoques, o que acarretou no crescimento da acuracidade destes. Prosseguindo-se, os objetivos específicos foram: descrever quais tecnologias de ERP integradas a curva $A B C$ apresentam-se no mercado; validar na empresa a aplicação dessas ferramentas; e quantificar a acuracidade obtida com a implementação das metodologias na panificadora. A interpelação e implantação de tais propostas concluíram-se mediante à utilização da ferramenta $5 \mathrm{~W} 2 \mathrm{H}$ e transcorreram-se da Fundamentação Teórica, onde, por sua vez, foram supramencionadas as estruturas prescritas nas ações.

Conclui-se este estudo apontando, diante dos resultados identificados e analisados, que, com a introdução do ERP's, guiado pela metodologia de Curva $A B C$, acarretou a maior evolução na ordenação dos itens em estoque e, por consequência, aprimorou a eficiência no controle dos produtos, o período de conservação e validade dos itens oferecidos aos clientes. Portanto, alcançou-se a acuracidade dos estoques e adequou-se o comportamento dos colaboradores da instituição e promoveu a padronização geral. 


\section{REFERÊNCIAS}

ALMEIDA, N. G. N. de. A importância da metodologia científica através do projeto de pesquisa para a construção da monografia. Revista de Biblioteconomia e Ciência da Informação, v. 2, n. 1, p. 57-66, 2016.

ARAGÃO NETO, J. H. M.; MENDES, M. A. H. Metodologia científica. $51^{\text {a }}$ ed. Salvador: UFBA, Faculdade de Educação, Superintendência de Educação a Distância, 2017.

FALSARELLA, O. M.; JANNUZZI, C. A. S. C.; SUGAHARA, C. R. Planejamento estratégico empresarial: proposta de um sistema de inteligência organizacional e competitiva. RDBCl: Revista Digital de Biblioteconomia e Ciência da Informação, v. 12, n. 2, p. 193-216, 2014.

FREITAS, M. M. B. C. de.; FRAGA, M. A. de. F; SOUZA, G. P. L. de. Logística 4.0: conceitos e aplicabilidade: uma pesquisa-ação em uma empresa de tecnologia para o mercado automobilístico. Caderno PAIC, v. 17, n. 1, p. 237-261, 2016.

GALLI, L. C. do. L. A. et al. O comportamento de compra dos consumidores do município de Jaboticabal-SP em relação aos serviços panificação: um estudo exploratório-descritivo. Brazilian Journal of Business, v. 2, n. 2, p. 1548-1560, 2020.

LEITE, A. S.; NASCIMENTO, V. C.; MATTEU, Douglas de. O Feedback nas Organizações: Técnicas e estratégias para fornecer um feedback. Revista de Humanidades, Tecnologia e Cultura, v. 8, n. 1, p. 1-11, 2018.

LEMES, E. A.; LIMA, E. M. Análise dos critérios utilizados em relação aos estoques obsoletos em uma empresa atacadista. Revista Mineira de Contabilidade, v. 19, n. 1, p. 68-79, 2018. 
MARTINS, E. R. Engenharia de produção: planejamento e controle da produção em foco. Guarujá: Científica Digital, 2021.

PAIM, A. S.; IAPPE, N. T.; ROCHA, D. L. B. Métodos de enseñanza utilizados por docentes del curso de enfermería: enfoque en la metodología de investigación. Enfermería global, v. 14, n. 37, p. 136-152, 2015.

PEREIRA FILHO, E.; CAMPOS, D. F.; NÓBREGA, K. C. A qualidade de serviços no Fast Food: um estudo das lacunas de percepção em um ambiente de shopping center. HOLOS, v. 1, p. 111-132, 2015.

PEREIRA, V. T.; CASTILHO, A. P.; BORGES, N. R. M. Manual de metodologia científica do ILES Itumbiara/GO. 1ํㅡㄹ. ed. Itumbiara: ILES/ULBRA, 2011.

SÁ, G. M. da. S. Capacitação profissional para um atendimento de excelência no Setor Público. 2016. 16f. Artigo (Bacharel em Administração Pública) Universidade Federal Fluminense, Niterói, RJ, 2016.

SANTOS, B. T. dos.; LUBIANA, C. O uso da curva ABC para a tomada de decisão na composição de estoque. Inter-American Journal of Development and Research, v. 1, n. 1, p. 62-78, 2017.

SANTOS, Crislane Arruda et al. Um modelo de sistema de informação gerencial: vantagem competitiva no processo da logística reversa do óleo de cozinha. Research, Society and Development, v. 4, n. 1, p. 62-88, 2017.

SANTOS, R.; GRACIANO NETO, V. V.; ARAUJO, R. Sistemas de sistemas de informação e ecossistemas de software: conceitos e aplicações. In: XIII Simpósio Brasileiro de Sistemas de Informação: Tópicos em Sistemas de Informação: Minicursos SBSI, 2017.

SHITSUKA, D. M. et al. Licenciatura em computação. Metodologia da pesquisa científica. $1^{\underline{a}}$ ed. Santa Maria: Universidade Federal de Santa Maria, 2018. 
SILVA, M. G.; RABELO, M. H. S. Importância do controle de estoques para as empresas. Revista Acadêmica Conecta FASF, v. 2, n. 1, p. 238-255, 2017.

SILVA, R. F. A. A da. O impacto competitivo da aplicação de novas tecnologias em centros de distribuição na gestão de estoques e na experiência do cliente: estudo de caso de uma empresa líder do setor logístico. 2020. 72f. Trabalho de Conclusão de Curso (Bacharel em Engenharia de Produção) - Universidade Federal Fluminense, Niterói, RJ, 2020.

SILVA, T. de. C. Estratégias de marketing digital voltadas a comercialização de alimentos: uma análise do perfil do consumidor de aplicativos de fast food. Goiás: Centro Universitário de Anápolis UniEvangélica, 2020.

SOUZA, T. E. S. et al. Metodologia científica: teoria e aplicação na educação a distância. $1^{\text {a }}$ ed. Petrolina: Fundação Universidade Federal do Vale do São Francisco, 2019.

STECCA, J. P.; ÁVILA, L. V. Gestão de Pessoas. Santa Maria: Universidade Federal de Santa Maria, Colégio Politécnico; Rede e-Tec Brasil, 2015.

VERAS JUNIOR, D. da. S. Avaliação da qualidade no setor de panificação: um estudo de caso na cidade de Caruaru. 2015. 64f. Trabalho de Conclusão de Curso (Bacharel em Administração) - Universidade Federal de Pernambuco, Recife, PE, 2015.

WILLE, M. M.; BORN, J. C. Logística reversa: conceitos, legislação e sistema de custeio aplicável. Revista de Administração e Ciências Contábeis, v. 8, 2012.

Enviado: Outubro, 2021.

Aprovado: Novembro, 2021. 